\title{
EDITORIAL
}

\section{OLD BONES}

\section{J.E. MORLEY}

Corresponding author: John E. Morley, MB, BCh, Division of Geriatric Medicine, Saint Louis University School of Medicine, 1402 S. Grand Blvd., M238, St. Louis, MO 63104, Email: john.morley@health.slu.edu

Key words: Osteoblasts, bone formation, fragility fractures.

Bone is a dynamic organ in which osteoblasts, under inhibitory control of sclerostin, creates new bone osteoblasts by releasing RANK-L to activate osteoclasts to remove bone. This dynamic network is under local control of miRNAs and long noncoding RNAs to balance the effect of bone stressors on bone formation (1).

With aging there is an increase in fragility fractures. Fractures are a more common reason for older persons requiring interaction with medical professionals than any other disease and are one of the higher components of annual hospital costs (2). Over $20 \%$ of older persons with hip fractures die within a year and they are a major cause of disability (3). Vertebral fractures are a major cause of back pain, loss of height, reduced pulmonary function, dysphagia, deformity and a decline in quality of life.

The need for collaboration between orthopedic surgeons and geriatricians to improve outcomes of older persons with fractures led to the forming of the first geriatric orthopaedic unit by Bobby Irvine and Michael Devas in 1963 (4). The motto of this unit was "Bedrest is rehabilitation for the grave." Richard Lefroy published the first positive effects of a geriatric orthopedic unit in Perth, Australia (5). A meta-analysis found that these combined programs resulted in a decrease in both in-hospital and long-term mortality (6). Two recent approaches improving hip fracture care are: (i) providing regional nerve blocks on arrival at hospital to reduce pain and improve function outcomes (7) and (ii) injection of a triphasic calcium based implant (AGN-1) into the contralateral proximal femur to reduce subsequent hip fracture in the other hip (8).

There are three major bone diseases in older persons Paget's disease of bone, osteomalacia, and osteoporosis.

\section{Paget's Disease of Bone}

Paget's disease is a bone disease in which rapid destriction by osteocytes is imbalanced with excess osteoblastic reformation. It is more common in males of 55 years of age. Over the last 30 years, it has decreased from $4-5 \%$ to 1 to $2 \%$ (9). While the reason for this decrease is uncertain it is suggested that it is due to vaccination for the paramyxovirus measles (10).

Paget's disease results in bone pain and deformity, fractures, deafness and high output heart failure. If there are characteristic findings on $\mathrm{x}$-rays an increased alkaline phosphatase can help confirm the diagnosis. Treatment is with intravenous infusion of the long acting biophosphonates, zoledronic acid.

\section{Osteomalacia}

Osteomalacia is weak bones that break easily because of less mineralization resulting in the bone breaking down at a greater rate than it forms. The major cause is vitamin D deficiency. Other causes are celiac disease, antiviral and antiepileptic drugs, intestinal bypass, kidney or liver disease (11).

The signs and symptoms of osteomalacia include dull bone pain, muscle pain and weakness, Looser's fractures, numbness and muscle twitching and a prolonged QT on ECG. Blood tests are a low calcium and phosphate and elevated alkaline phosphatase and parathormone levels. Diagnostic is low bioavailable $25(\mathrm{OH})$ vitamin $\mathrm{D}$. Total vitamin $\mathrm{D}$ levels are variable depending on the color of the skin and as such are no longer recommended $(12,13)$. Treatment is replacement with about 1,000 IU of vitamin D daily.

\section{Osteoporosis}

Osteoporosis is a decrease in bone mineralization in older persons leading to weakness of bones and subsequent fracture. Osteoporosis is dependent on the size of bones built during childhood. It is related to a number of genetic factors especially RANK/RANK ligand/osteoprogenin, WNT and estrogen receptor 1 (14). Osteoporosis is often not recognized nor treated by physicians. For this reason, screening is recommended in all women between 50 to 60 years of age and males over 70 years of age. Screening is done utilizing the FRAX (WHO Fracture Risk Assessment: www.shef.ac.uk/FRAX). Risk factors for osteoporosis can be remembered by the mnemonic OSTEOPOROSIS (Table 1) together with diseases such as diabetes mellitus and COPD. If risk factors are present bone mineral density (BMD) should be measured using a dual energy x-ray absorptiometry (DEXA) scan. Rate of bone loss is important to detect persons at risk for developing osteoporosis. The DEXA should be repeated every 2 years, but because of seasonal fluctuations in bone calcification it should be done in 


\section{THE JOURNAL OF NUTRITION, HEALTH \& AGING}

the same month. In persons with diabetes mellitus, the DEXA often shows high mineralization but the bones have weak structure. Ultrasound of the tibia is an alternative approach. A recent approach to screening and management has been developed (Figure 1) (15).

Table 1

Risk Factors for Osteoporosis: The Osteoporosis Mnemonic

Low calcium intake

Seizure medications

Thin build/weight loss

Ethanol

Hyp $\underline{\text { Ogonadin }}$

Prior fractures

Thyroid excess

$\underline{\text { Race }}$

Other relatives

Steroids

Inactivity

Smoking

\section{Figure 1}

Hypothetical approach to screening and treating osteoporosis in women. In general treatment should be driven by FRAX score

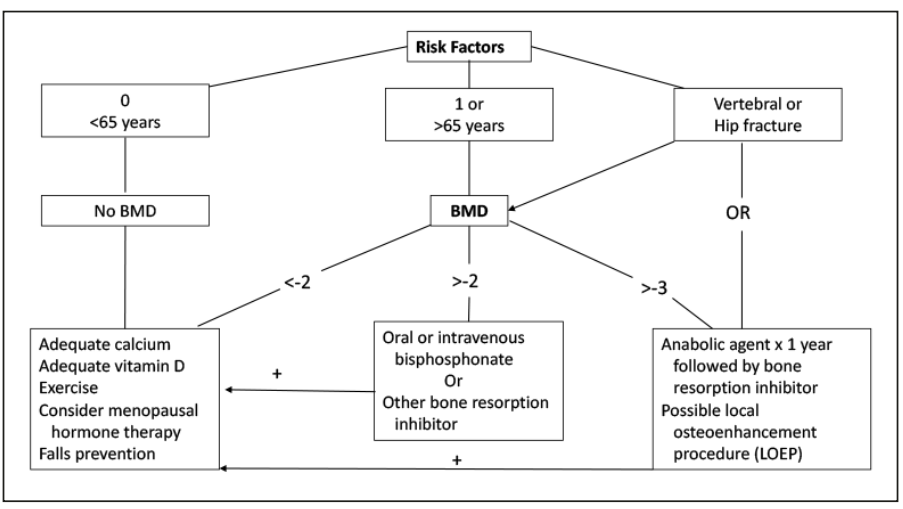

Persons with osteoporosis need adequate daily calcium intake, which is about $1 \mathrm{~g}$ a day. Higher total calcium intake leads to increased cardiovascular disease and mortality (16). The average female ingests $600 \mathrm{mg}$ per day and males about $800 \mathrm{mg}$ per day. If calcium is to be replaced it needs to be given at night (as calcium comes off bone while lying in bed). It can best be replaced with one $8 \mathrm{oz}$ low fat yogurt.

In persons with a white skin the normal value of $25(\mathrm{OH})$ vitamin $\mathrm{D}$ is 20 to $25 \mathrm{ng} / \mathrm{ml}(50-75 \mathrm{nmol} / \mathrm{L})(17)$. In dark skinned persons there is a reduction in vitamin $\mathrm{D}$ binding protein and in these individuals bioavailable $25(\mathrm{OH})$ vitamin $\mathrm{D}$ should be measured. There is no need to replace vitamin D at more than $1000 \mathrm{IU} / \mathrm{day}$.

\section{Drugs for Osteoporosis}

Estrogen is needed for all women with premature menopause or with menopausal symptoms (18). In general, it is not recommended that estrogen be taken for more than 5 years. It decreases hip fracture. Raloxifene increases bone mineral density, reduces spine fractures and a $65 \%$ reduction in breast cancer (19).

Alendronate, a bisphosphonate, enhances bone mineral density and decreases hip fractures (20). Its main side effects are esophagitis, uveitis, esophageal cancer, osteonecrosis of the jaw and atypical femoral diaphyseal fractures. It needs to be recognized that alendronate decreases hip fractures to a much greater extent than it causes atypical fractures (21). For persons who cannot take alendronate orally, intravenous zoledronic acid is recommended (22).

Denosumab is a human monoclonal antibody that blocks RANK ligand (23). Denosumab is given by subcutaneous injection every 6 months. It has a similar effectiveness to bisphosphonates and the same side effects. In addition, it causes skin infections, such as cellulitis. It is much more expensive than bisphosphonates.

Two parathormone analogs, teriparatide and abaloparatide are available for persons with severe osteoporosis ( $\mathrm{T}$ score $<-3.0)$ or severe hip fractures (24-26). They are anabolic agents which are recommended not to be taken for longer than 2 years: A number of different delivery mechanisms (e.g., nasal, patch, microchips) are available for teriparatide.

Sclerostin is an antagonist of the $\mathrm{Wnt} / \beta$-catenin signaling pathway. An antibody to sclerostin, romosozumab, is available as an anabolic agent which markedly increases bone mineral density and decreases vertebral fractures (27). Its use should be limited to 12 months. It causes ectopic calcification and it can cause myocardial infarction. It also causes arthralgia.

Testosterone increases bone mineral density in men but there have been no large controlled studies to show that it prevents hip fracture (28). In addition, to improving BMD it increases bone strength (29).

\section{Conclusion}

Diseases of old bone result in an increase in hip fracture. These bone diseases are often under-recognized and undertreated by physicians in older persons. Table 2 provides approximate prices of drugs for osteoporosis. Physicians should take these costs into account when choosing treatments.

In persons at risk for hip fracture, besides strengthening the bones it is essential that physicians pay attention to fall risk. The Toulouse-St. Louis University MiniFalls test should be used (30) along with the F3ALLS treatment paradigm (31). In addition, all persons at risk for fracture should be screened for frailty - using the FRAIL - and treated with the frail algorithm 


\section{OLD BONES}

(32-36). In addition, sarcopenia should be screened for using the SARC-F and if present, be appropriately managed (37-39).

Table 2

Cost of Medications for Osteoporosis in the USA

\begin{tabular}{ll}
\hline Medication & Cost/Year \\
\hline Vitamin D & $\$ 72$ \\
Alendronate & $\$ 120$ \\
Zoledronic acid & $\$ 1,173$ \\
Denosumab & $\$ 1,650$ \\
Teriparatide & $\$ 6,700$ \\
Romosozumab & $\$ 21,900$ \\
\hline
\end{tabular}

Disclosures: Dr. Morley as having no conflicts to declare.

\section{References}

1. Zhou Y, Xu C, Zhu W, et al. Long noncoding RNA analyses for osteoporosis risk in Caucasian women. Calcif Tissue Int 2019;105:183-192.

2. Morley JE. Hip fractures. J Am Med Dir Assoc 2010;11:81-83.

3. Sanford AM, Morley JE, McKee A. Editorial: Orthogeriatrics and hip fractures. J Nutr Health Aging 2018;22:457-462.

4. Devas MB. Geriatric Orthopaedics. Br Med J 1974;1(5900):190-192.

5. Lefroy RB. Treatment of patients with fractured neck of the femur in a combined unit. Med J Aust 1980;2:669-670.

6. Grigoryan KV, Javedan H, Rudolph JL. Orthogeriatric care models and outcomes in hip fracture patients: A systematic review and meta-analysis. J Orthop Trauma 2014;28:e49-55.

7. Scurrah A, Shiner CT, stevens JA, Faux SG. Regional nerve blockade for early analgesic management of elderly patients with hip fracture - a narrative review. Anaesthesia. 2018;73:769-783.

8. Howe JG, Hill RS, Stroncek JD, et al. Treatment of bone loss in proximal femurs of postmenopausal osteoporotic women with AGN1 local osteo-enhancement procedure (LOEP) increases hip bone mineral density and hip strength: A long-term prospective cohort study. Osteoporos Int 2019;Dec 4 doi: 10.1007/s00198-019-05230-0 [Epub ahead of print]

9. Michou L, Orcel P. The changing countenance of Paget's disease of bone. Joint Bone Spine 2016;83:650-655.

10. Sundaram K, Sambandam Y, Shanugarajan S, et al. Measles virus nucleocapsid protein modulates the signal regulatory protein- $\beta 1$ (SIRP $\beta 1$ ) to enhance osteoclast differentiation in Paget's disease of bone. Bone Rep 2016;7:26-32.

11. Zimmerman L, McDeon B. Osteomalacia. StatPearls Publishing LLC. 2020. www. ncbi.nlm.nih.gov/pubmed/31869080

12. McKee A, Lima Ribeiro SM, Malmstrom TK, et al. Screening for vitamin D deficiency in black Americans: Comparison of total, free, bioavailable 25 hydroxy vitamin D levels with parathyroid hormone levels and bone mineral density.

13. Merchant RA, van Dam RM, Tan LWL, et al. Vitamin D binding protein and vitamin D level in multi-ethnic population. J Nutr Health Aging 2018;22:1060-1065.

14. Styrkarsdottir U, Halldorsson BV, Gretarsdottir S, et al. Multiple genetic loci for bone mineral density and fractures. N Engl J Med 2008;358:2355-2365.

15. Kanis JA, Harvey NC, Johansson H, et al. A decade of FRAX: How has it changed the management of osteoporosis? Aging clin Exp Res 2020;32:187-196.
16. Michaelssen K, Melhus H, Warensjo Lemming E, et al. Long term calcium intake and rates of all cause and cardiovascular mortality: Community based prospective longitudinal cohort study. BMJ 2013;346:f228.

17. Morley JE. Editorial: Vitamin D: Does the emperor have no clothes? J Nutr Health Aging 2019;23:316-317.

18. Minkin MJ. Menopause: ormones, lifestyle, and optimizing aging. Obstet Gynecol Clin North Am 2019;46:501-514.

19. Ettinger B, Black DM, Mitlak BH, et al. Reduction of vertebral fracture risk in postmenopausal women with osteoporosis treated with raloxifene: Results from a 3-year randomized clinical trial. Multiple outcomes of raloxifene evaluation (MORE) investigators. JAMA 1999;282:637-645.

20. Black DM, Rosen CJ. Clinical practice. Postmenopausal osteoporosis. N Engl J Med 2016;374:254-262.

21. Black DM, Abrahamsen B, Bouxsein ML, et al. Atypical femur fractures; review of epidemiology, relationship to bisphosphonates, prevention, and clinical management. Endocr Rev 2019;40:333-368.

22. Dhillon S. Zoledronic acid (Reclast ${ }^{\circledR}$, Aclasta $\left.{ }^{\circledR}\right)$ : A review in osteoporosis. Drugs. 2016;76:1683-1697.

23. Deeks ED. Denosumab: A review in postmenopausal osteoporosis. Drugs Aging 2018;35:163-173.

24. Shi Z, Zhou H, Pan B, et al. Effectiveness of teriparatide on fracture healing: A systematic review and meta-analysis. PLoS One 2016;11(12):e0168691. Doi 10.1371/journal.pone.0168691. eCollection 2016.

25. Chen Q, Guo M, Ma X, et al. Adherence to teriparatide treatment and risk of fracture: A systematic review and meta-analysis. Horm Metab Res 2019;51:785-791. Doi: 10.1055/a-1062-9447.

26. Miller PD, Hattersley G, Rijs BJ, et al; ACTIVE Study Investigators. Effect of abaloparatide vs placebo on new vertebral fractures in postmenopausal women with osteoporosis: A randomized clinical trial. JAMA 2016;316:722-733.

27. Saaq KG, Petersen J, Brandi ML, et al. Romosozumab or alendronate for fracture prevention in women with osteoporosis. N Engl J Med 2017;377:1417-1427.

28. Isidori AM, Giannetta E, Greco EA, et al. Effects of testosterone on body composition, bone metabolism and serum lipid profile in middle-aged men: A metaanalysis.

29. Snyder PJ, Peachey H, Hannoush P, et al. Effect of testosterone treatment on body composition and muscle strength in men over 65 years of age. J Clin Endocrinol Metab 1999;84:2647-2653.

30. Rouck JE, Malmstrom TK, Morley JE. Initial validation of the Toulouse - St. Louis University Mini Falls assessment in older adults. J Nutr Health Aging 2018;22:880884.

31. Morley JE. F3ALLS approach to preventing falls. J Nutr Health Aging 2018;22:748 750 .

32. Woo J, Yang X, Tin Lui L, et al. Utility of the FRAIL questionnaire in detecting heart failure with preserved ejection fraction. J Nutr Health Aging 2019;23:373-377.

33. Berry SD, Zullo AR, Zhang T, et al. Validation of the FRAIL model to predict nonvertebral and hip fractures in nursing home residents. Bone. 2019;128:115050. DOI: 10.1016/j.bone.2019.115050. Epub 2019 Aug 28.

34. Dent E, Morley JE, Cruz-Jentoft AJ, et al. Physical frailty: ICFSR international clinical practice guidelines for identification and management. J Nutr Health Aging 2019;23:771-787.

35. Dent E, Lien C, Lim WS, et al. The Asia-Pacific clinical practice guidelines for the management of frailty. J Am Med Dir Assoc 2017;18:564-575.

36. Morley JE. The new geriatric giants. Clin Geriatr Med 2017;33:xi-xii. Doi: 10.1016/j. cger.2017.05.001.

37. Dent E, Morley JE, CruzJentoft AJ, et al. International clinical practice guidelines for sarcopenia (ICFSR): Screening, diagnosis and management. J Nutr Health Aging 2018;22:1148-1161.

38. Ha YC, Won Won C, Kim M, et al. SARC-F as a useful tool for screening sarcopenia I elderly patients with hip fractures. J Nutr Health aging 2020;24:78-82.

39. Chen H, Ma J, Liu A, et al. The association between sarcopenia and fracture in middle-aged and elderly people: A systematic review and meta-analysis of cohort studies. Injury 2020;Feb 18 DOI: 10.1016/j.injury.2020.02.072 [Epub ahead of print]. 